\title{
The diagnostic pathway embolism: from the Emergency Department to the Internal Medicine Unit
}

\author{
Attilia Maria Pizzini, ${ }^{1}$ Daniela Galimberti, ${ }^{1}$ Stefano De Pietri, ${ }^{2}$ Mauro Silingardi, ${ }^{3}$ Maria Cristina Leone,${ }^{1}$ \\ Annamaria Ferrari, ${ }^{2}$ Ido Iori ${ }^{1}$ \\ ${ }^{1}$ Medicine I, Hemostasis and Thrombosis Center, Arcispedale Santa Maria Nuova - IRCCS, Reggio Emilia; ${ }^{2}$ Department of \\ Emergency-Urgency, Arcispedale Santa Maria Nuova - IRCCS, Reggio Emilia; ${ }^{3}$ Complex Operating Unit of Internal Medi- \\ cine, Ospedale Civile of Guastalla, Reggio Emilia, Italy
}

\begin{abstract}
The diagnostic pathway of pulmonary embolism, both in the Emergency Department and in the Medical Unit, is not a standardized one. Pulmonary embolism, often but not always complicating surgery, malignancies, different medical diseases, sometimes but not often associated with a deep vein thrombosis, is not infrequently a sudden onset life-threatening and rapidly fatal clinical condition. Most of the deaths due to pulmonary embolism occur at presentation or during the first days after admission; it is therefore of vital importance that pulmonary embolism should promptly be diagnosed and treated in order to avoid unexpected deaths; a correct risk stratification should also be made for choosing the most appropriate therapeutic options. We review the tools we dispose of for a correct clinical assessment, the existing risk scores, the advantages and limits of available diagnostic instruments. As for clinical presentation we remind the great variability of pulmonary embolism signs and symptoms and underline the importance of obtaining clinical probability scores before making requests for further diagnostic tests, in particular for pulmonary computer tomography; the Wells score is the only in-hospital validated one, but unfortunately is still largely underused. We describe our experience in two different periods of time and clinical settings in the initial evaluation of a suspected pulmonary embolism; in the first one we availed ourselves of a computerized support based on Wells score, in the second one we did not. Analysing the results we obtained in terms of diagnostic yield in these two periods, we observed that the computerized support system significantly improved our pulmonary embolism diagnostic accuracy.
\end{abstract}

\section{Introduction}

Symptomatic venous thromboembolism occurs in 1-2 per 1000 adults each year; a third of these patients present with pulmonary embolism, ${ }^{1}$ which is the most common cause of vascular death after myocardial infarction and stroke. Symptomatic pulmonary em-

Correspondence: Attilia Maria Pizzini, Medicine I, Hemostasis and Thrombosis Center, Arcispedale Santa Maria Nuova IRCCS, viale Risorgimento 80, 42100 Reggio Emilia, Italy. Tel.: +39.0522.295832 - Fax: +39.0522.296853.

E-mail: attilia.pizzini@asmn.re.it

Key words: Pulmonary embolism; clinical pre-test-probability; pulmonary computed tomography; computerized decision support system.

Received for publication: 26 September 2014.

Revision received: 10 June 2015.

Accepted for publication: 19 June 2015.

This work is licensed under a Creative Commons Attribution NonCommercial 4.0 License (CC BY-NC 4.0).

CCopyright A.M. Pizzini et al., 2016

Licensee PAGEPress, Italy

Italian Journal of Medicine 2016; 10:4-9

doi:10.4081/itjm.2016.546 bolism is thought to be rapidly fatal in $10 \%$ of cases, plus $5 \%$ after starting treatment. About $2 \%$ of pulmonary embolism patients develop thromboembolic pulmonary hypertension. ${ }^{1,2}$

This is why the diagnostic pathway, both in the emergency unit and in the medical department, should be guided by two principles: i) a fast and accurate identification of patients affected, as a diagnostic delay might be fatal and a diagnostic mistake might increase the bleeding risk; and ii) a correct risk stratification, in order to choose the most appropriate treatment. ${ }^{3,4}$

Diagnostic scores (Wells and Geneva) and principal markers for pulmonary embolism risk stratification (hypotension-shock, markers of right ventricular dysfunction or myocardial injury), together with the optimal radiological and laboratory testing [scintigraphy and computed tomography (CT) scan, D-dimer], can lead to a prompt diagnosis and address the patient to the most appropriate in-hospital pathway (discharge, admission or intensive care unit). We describe the diagnostic pathway, based on the evidence from literature, which we adopted in our hospital.

\section{Discussion}

The clinical presentation of acute pulmonary embolism varies widely among patients, depending on 
the extension itself and on the possible underlying cardiopulmonary impairment. ${ }^{4,5}$ As pulmonary embolism symptoms are totally non-specific and heterogeneous, a correct initial assessment is essential in order to rule in and rule out pulmonary embolism as well as to identify the patients who would benefit from an early aggressive treatment. ${ }^{6}$ We suggest that a clinical pretest-probability of $85 \%$ or more could be the threshold that rules in pulmonary embolism and justifies anticoagulant therapy; this correlates to a moderate or high clinical suspicion. Conversely, the threshold that rules out pulmonary embolism, advising against anticoagulant therapy, is a probability pre-test $\leq 2 \%{ }^{6-8}$ Two validated scores are widely used: the Wells score ${ }^{9}$ and the revised Geneva one ${ }^{10}$ (Tables 1 and 2). We refer mainly to the Wells score, validated in inpatients; Geneva score is reserved to outpatients. The Wells score, which we consider the first step to address the choice of subsequent tests, consists of seven variables (Table 1) that allows to classify patients in pulmonary embolism likely ( $>4$ points) or unlikely ( $\leq 4$ points) (Figure 1). ${ }^{3,4,6,11}$

The next step, after evaluating the pre-test-probability, is the $\mathrm{D}$-dimer assay. The $\mathrm{D}$-dimer, a specific fragment of the fibrin clot, reflects the hemostatic balance steady state and has strong intra-individual variability. ${ }^{12}$ It is a highly sensitive test $(\geq 95 \%$ for quantitative ELISA or automated turbidimetric assays)

Table 1. Clinical prediction rule: Wells score.

\begin{tabular}{|c|c|c|}
\hline Variables & Points & \\
\hline Clinical signs of deep venous thrombosis & 3 & \\
\hline Alternative diagnosis less likely than pulmonary embolism & 3 & \\
\hline Heart rate $>100$ beats $/ \mathrm{min}$ & 1.5 & \\
\hline Immobilization or surgery in previous 4 weeks & 1.5 & \\
\hline History of venous thromboembolism & 1.5 & \\
\hline Hemoptysis & 1 & \\
\hline Malignancy or treatment for it in previous 6 months & 1 & \\
\hline Score interpretation & Points & Prevalence \\
\hline \multicolumn{3}{|l|}{ Pulmonary embolism likely:* } \\
\hline High probability & $\geq 6.5$ & $60 \%$ \\
\hline Moderate probability & $4.5-6$ & $25 \%$ \\
\hline \multicolumn{3}{|l|}{ Pulmonary embolism unlikely: } \\
\hline Low probability & $\leq 4$ & $5 \%$ \\
\hline
\end{tabular}

Table 2. Clinical prediction rule: revised Geneva score for pulmonary embolism.

\begin{tabular}{|c|c|}
\hline Variables & Points \\
\hline Previous deep venous thrombosis or pulmonary embolism & 3 \\
\hline Heart rate $75-94$ beats/min & 3 \\
\hline Heart rate $\geq 95$ beats $/ \mathrm{min}$ & 5 \\
\hline Pain on deep vein palpation in leg and unilateral edema & 4 \\
\hline \multicolumn{2}{|l|}{ Unilateral leg pain 3} \\
\hline Surgery (under general anesthesia) or fracture (of the lower limbs) within 1 month & 2 \\
\hline Hemoptysis & 2 \\
\hline Active malignancy & 2 \\
\hline Age $>65$ years & 1 \\
\hline $\begin{array}{l}\text { A score }<2 \text { are at low risk } \\
2-6 \text { are at intermediate risk } \\
\geq 6 \text { are at high risk }\end{array}$ & \\
\hline
\end{tabular}


with a strong negative predictive value. D-dimer testing should be evaluated together with pre-test probability calculation (Figure 1). The combination of a normal, high-sensitive, quantitative D-dimer test result and an unlikely clinical probability has a negative predictive value; alone it can rule out acute pulmonary embolism without further imaging. On the contrary all patients with an elevated D-dimer or a clinical evaluation of likely probability should be referred to radiological evaluation. ${ }^{6,13}$ Thanks to these two simple tests we could be able to diagnose acute pulmonary embolism, thus postponing CT-scan or scintigraphic evaluation. Despite the simple feasibility of the above-mentioned tests, Wells score is little known and surely underused, while D-dimer assay is misused. Ddimer is frequently part of the so-called coagulation test list, which is often requested without a reasonable motive, stirring up further expensive and sometimes useless diagnostic tests. D-dimer has little specificity as several medical conditions, pathological or not, can give rise to elevated levels (Table 3 ): ${ }^{14-16}$ it should be used with caution in in-hospital patients, since numerous diseases and invasive procedures can rise its levels in the absence of thrombosis. Furthermore, D-dimer assays should not be used in anticoagulated (heparin or warfarin) patients: clinical studies have demonstrated that anticoagulants decrease circulating Ddimer levels, thus causing a false negative value. It is suggested that D-dimer testing should not be used as a screening test for pulmonary embolism. ${ }^{15,16}$

The radiological diagnostic instruments are scintigraphy and pulmonary CT scan. Today the first one is seldom used as CT-scan is the gold standard exam: scintigraphy should be performed only in patients with renal insufficiency, contrast hypersensitivity, in younger patients in whom scintigraphy has a greater specificity, and in any case if chest -ray is negative. ${ }^{3,17,18}$ In the last years computed tomography pulmonary angiography has become the gold standard diagnostic tool for suspected pulmonary embolism. Lung CT-scan is readily available in many hospitals and has been shown to have a high sensitivity and specificity. ${ }^{19,20}$ Its easy accessibility and great sensitivity have led to a remarkable increase in its use, even though this approach is not always correct. The percentage of positive CT-scan examinations ranges from $20 \%$ in controlled multicenter trials to less than $10 \%$ in observational ones. ${ }^{3,19}$ Its overutilization not only

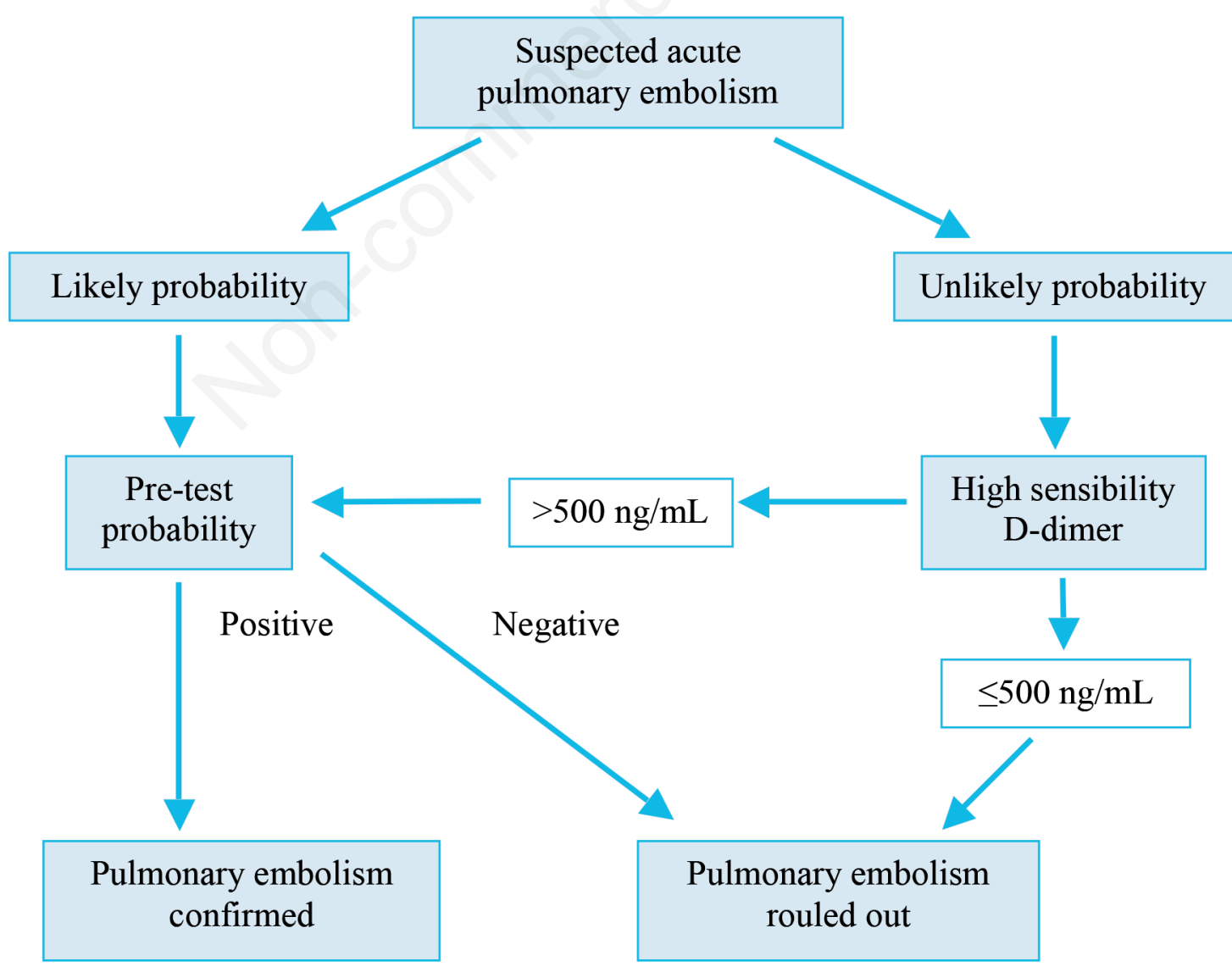

Figure 1. Diagnostic algorithm for clinically suspected pulmonary embolism. 
exposes the patient to radiation and contrast kidney disease risk, ${ }^{21,22}$ but it is weighed as well by exceeding costs; costs that are enhanced by overtreatment of incidental pulmonary embolism, that should not be treated at all. ${ }^{8,21}$ Despite the undoubted advantage of this tool in the diagnostic pathway of thrombosis, its use should be targeted and limited to patients with a high pre-test clinical probability or an elevated Ddimer test. ${ }^{3,6}$

Lastly, if lower limbs compression ultrasound, which should precede imaging tests in pregnant women and in patients with a contraindication to $\mathrm{CT},{ }^{4,23-25}$ is performed as a first step, CT or scintigraphy could be avoided in about $10 \%$ of patients. A diagnosis of proximal venous thrombosis in a symptomatic and hemodynamically stable patient, or in an asymptomatic patient who has contraindications to CT, is considered a sufficient criterion for pulmonary embolism diagnosis. ${ }^{25}$

\section{Integrated approach}

To improve CT-scan diagnostic performance, and at the same time to safely rule out pulmonary embolism, diagnostic algorithms and predictive scores have been elaborated; in spite of their appropriateness and easy applicability, they are unfortunately seldom used in clinical practice. ${ }^{20}$

We have compared the number of CT and of perfusional lung scan performed in the Emergency Department during two consecutive periods, each one of 15

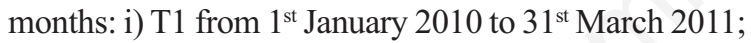
and ii) T2 from $1^{\text {st }}$ April 2011 to $30^{\text {th }}$ June 2012. During the first period a computerized system ${ }^{26-30}$ to support the decisional pathway was adopted in the Emergency Department. The computerized system was an integrated approach to the radiological request which consisted in the mandatory filling of every Wells score field by the emergency physician (Table 4). Only in case of high pre-test probability the CT-scan request was accepted by the radiological department. It was possible to bypass this procedure only by a written request or by a direct telephone call to the radiologist (Figure 2). ${ }^{26}$
During the first 15 months (T1) a total of 48 pulmonary embolism diagnoses were made (data extrapolated from diagnosis-related groups), similarly to what happened in T2 (49 pulmonary embolism diagnoses). However in T1, thanks to the computerized support, a relevant decrease in the number of $\mathrm{CT}$ requests was observed in contrast to what happened in T2 (55 versus 95). The outcome was an improved diagnostic management and a related better diagnostic yield.

Moreover both during the first (T1) and the second (T2) period the number of lung scans to diagnose pulmonary embolism was considerably reduced in com-

Table 3. Conditions of increased plasma D-dimer.

\begin{tabular}{l}
\hline Advanced age and newborn period \\
\hline Pregnancy, physiological and pathological (including puerperium) \\
\hline Functional disabilities \\
\hline Infection (especially Gram-negative) \\
\hline Cancer \\
\hline Surgery \\
\hline Trauma and burns \\
\hline Disseminated intravascular coagulation \\
\hline Venous thromboembolism \\
\hline Ischemic heart disease and congestive heart failure \\
\hline Stroke \\
\hline Arterial occlusive and aneurysmatic disease \\
\hline Sickle cell anemia with hemolytic crisis \\
\hline Cerebral hemorrhages \\
\hline Other bleedings \\
\hline Acute respiratory distress syndrome \\
\hline Liver and kidney disease \\
\hline Inflammatory bowel disease \\
\hline Chronic inflammatory diseases (e.g., lupus, rheumatoid arthritis) \\
\hline Thrombolytic therapy \\
\hline ing
\end{tabular}

Table 4. Integrated approach.

\begin{tabular}{|c|c|c|}
\hline & $\begin{array}{c}\text { T1 } \\
\text { from } 1^{\text {st }} \text { January } 2010 \text { to } \\
\text { 31 }^{\text {st }} \text { March } 2011\end{array}$ & $\begin{array}{c}\text { T2 } \\
\text { from } 1^{\text {st }} \text { April } 2011 \text { to } \\
\text { 30 }^{\text {th }} \text { June } 2012\end{array}$ \\
\hline Number of patients studied for pulmonary embolism & 314 & 307 \\
\hline Number of pulmonary embolism diagnoses & 48 & 49 \\
\hline Number of perfusion scan & 7 & 1 \\
\hline Number of computed tomography-scan & 55 & 95 \\
\hline
\end{tabular}




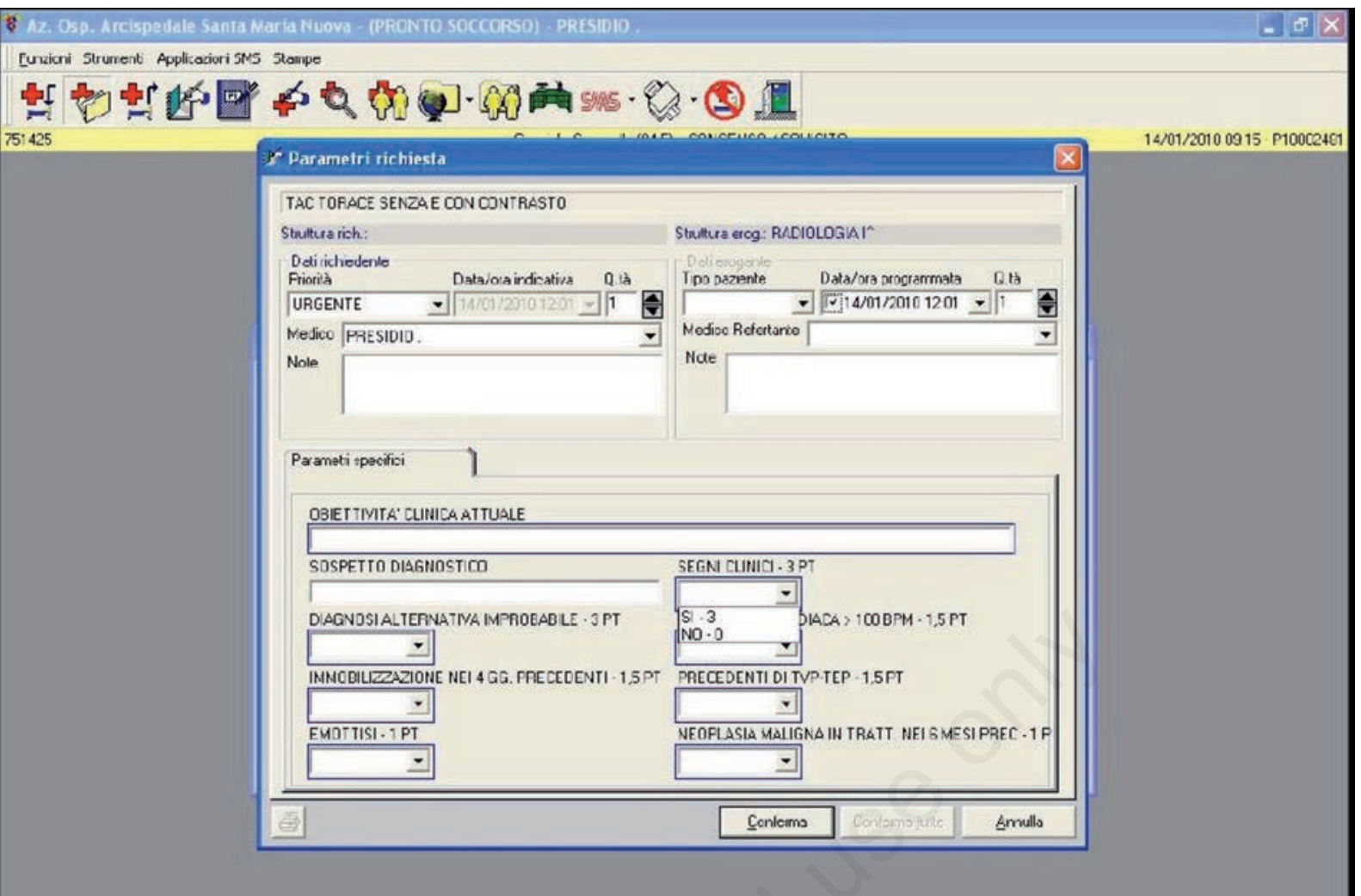

Figure 2. The computerized decision support system used in Emergency Department in T1-T2.

parison with the previous years (only 7 in T1 and T2), thus showing the little role of this diagnostic tool.

Unfortunately the relevant turnover in the Emergency Department medical staff and especially the information systems rearrangement have led to the abandonment of this method.

\section{Conclusions}

The data emerging from this simple survey are very interesting and we propose to resume the T1 method applying it to the new diagnostic requests system (named Aurora) and extending the computerized request system to D-dimer test as well.

We hope that our positive experience with computerized support during the T1 period may be exported to suburban hospitals, where it could represent a guide to Emergency medical staff improving the diagnostic yield and avoiding useless expensive examinations.

\section{References}

1. Heit JA. The epidemiology of venous thromboembolism in the community. Arteriosclerosis Thromb Vasc Biol 2008;28:370-2.

2. Naess IA, Christiansens SC, Romundstad P, et al. Inci- dence and mortality of venous thrombosis: a populationbased study. J Thromb Haemost 2007;5:692-9.

3. Agnelli G, Beccattini C. Acute pulmonary embolism. N Engl J Med 2010;363:266-74.

4. Goldhaber SZ, Bounameaux H. Pulmonary embolism and deep vein thrombosis. Lancet 2012;379:1835-46.

5. Takach Lapner S, Kearon C. Diagnosis and management of pulmonary embolism. BMJ 2013;346:f757.

6. Huisman MV, Klok AF. How I diagnose acute pulmonary embolism. Blood 2013;121:4443-8.

7. Van Belle A, Büller HR, Huisman MV, et al. Effectiveness of managing suspected pulmonary embolism using an algorithm combining clinical probability, D-dimer testing, and computed tomography. JAMA 2006;295: 172-9.

8. Konstantinides SV. Acute pulmonary embolism revisited. Heart 2008;94:795-802.

9. Wells PS, Ginsberg JS, Anderson DR, et al. Use of a clinical model for safe management of patients with suspected pulmonary embolism. Ann Intern Med 1998;129: 997-1005.

10. Le Gal G, Righini M, Roy PM, et al. Prediction of pulmonary embolism in the emergency department: the revised Geneva score. Ann Intern Med 2006;144:165-71.

11. Gibson NS, Sohne M, Kruip MJ, et al. Christopher study investigators. Further validation and semplification of the Wells clinical decision rule in pulmonary embolism. Thromb Haemost 2008;99:229-34.

12. Bruinstroop E, van de Ree MA, Huisman MV. The use of D-dimer in specific clinical conditions: a narrative review. Eur J Intern Med 2009;20:441-6. 
13. Di Nisio M, Squizzato A, Rutjes AW, et al. Diagnostic accuracy of D-dimer test for exclusion of venous thromboembolism: a systematic review. J Thromb Haemost 2007;5:296-304.

14. Righini M, Perrier A, De Moerloose P, Bounameaux H. D-dimer for venous thromboembolism diagnosis: 20 years later. J Thromb Haemostas 2008;6:1059-71.

15. Jaffrelot M, Le Ven F, Le Roux PY, et al. External validation of a D-dimer age-adjusted cut-off for the exclusion of pulmonary embolism. Thromb Haemost 2012; 107:1005-7.

16. Douma RA, Le Gal G, Söhne M, et al. Potential of an age adjusted D-dimer cut-off value to improve the exclusion of pulmonary embolism in older patients: a retrospective analysis of three large cohorts. BMJ 2010;340:c1475.

17. The PIOPED Investigators. Value of the ventilation/perfusion scan in acute pulmonary embolism. Results of the prospective investigation of pulmonary embolism diagnosis (PIOPED). JAMA 1990;263:2753-9.

18. Anderson DR, Kahn SR, Rodger MA, et al. Computed tomographic pulmonary angiography vs ventilation-perfusion lung scanning in patients with suspected pulmonary embolism: a randomized controlled trial. JAMA 2007;298:2743-53.

19. Mos IC, Klok FA, Kroft LJ, et al. Safety of ruling out acute pulmonary embolism by normal computed tomography pulmonary angiography in patients with an indication for computed tomography: systematic review and meta-analysis. J Thromb Haemost 2009;7:1491-8.

20. Douma R, Mos IC, Erkens P, et al. Performance of 4 clinical decision rules in the diagnostic management of acute pulmonary embolism. Ann Intern Med 2011; 154:709-18.

21. Stein PD, Fowler SE, Goodman LE, et al. Multidetector computed tomography for acute pulmonary embolism. N Engl J Med 2006;354:2317-27.

22. Sarma A, Heilbrun ME, Conner KE, et al. Radiation and chest CT scan examinations: what do we know? Chest 2012;142:750-60.

23. Le Gal G, Righini M, Sanchez O, et al. A positive compression ultrasonography of the lower limb veins is highly predictive of pulmonary embolism on computed tomography in suspected patients. Thromb Haemost 2006;95:963-6.

24. Johnson SA, Stevens SM, Woller SC, et al. Risk of deep vein thrombosis following a single negative whole-leg compression ultrasound: a systematic review and metaanalysis. JAMA 2010;303:438-45.

25. Kearon C, Akl EA, Comerota AJ, et al. Antithrombotic therapy for VTE disease: Antithrombotic Therapy and Prevention of Thrombosis, $9^{\text {th }}$ ed: American College of Chest Physicians Evidence-based Clinical Practice Guidelines. Chest 2012;141:e419-94S.

26. Drescher F, Chandrika S, Weir ID, et al. Effectiveness and acceptability of a computerized decision support system using modified Wells criteria for evaluation of suspected pulmonary embolism. Ann Emerg Med 2011;57:613-21.

27. Raja A, Ip I, Prevedello L, et al. Effect of computerized clinical decision support on the use and yeld of CT pulmonary angiography in the Emergency Department. Radiology 2012;262:468-74.

28. Blumenthal D. Stimulating the adoption of health information technology. N Engl J Med 2009;360:1477-9.

29. Jha AK. Meaningful use of electronic health records: the road ahead. JAMA 2010;304:1709-10.

30. Khorasani R. Computerized physician order entry and decision support: improving the quality of care. RadioGraphics 2001;21:1015-8. 